\title{
Building Biographies: Chronicling Time in Architectural Representation
}

\author{
PRIYA JAIN \\ Texas A\&M University
}

\begin{abstract}
Architectural drawings serve a strategic purpose- they are 'blueprints' to facilitate a building's construction. But what happens after construction is 'finished'? As the building moves through time, how does it deal with documenting its change? This paper deals with the issue of representing 'time' architecturally-- through an analysis of historical and contemporary examples, it investigates how the life of a building is chronicled. Is there any merit in tracking and representing this change beyond its immediate value of facilitating a modification. Whether and how does the conscious and deliberate 'drawing of time' inform architectural practice?
\end{abstract}

Buildings are not generally thought of as ephemeral objects. They inspire feelings of rigidity and permanence, of endurance and sustainability. Their mortal inhabitants come and go, but the physical space routinely endures through generations. For that fraction of buildings that are designed by architects, this cycle is typically set in motion by a client's vision, an architect's sketch, and subsequent renderings and construction drawings that delineate an 'imagined future'. What follows is the 'actual' act of building, almost always resulting in a structure that is a version of its imagined being. The design drawings live on, either physically or digitally, though devoid of their purpose as a 'blueprint'. They are at times updated to serve as 'as-built' documents, and at times picked up to draw over and inform future modifications. As the building moves through time, how does it deal with documenting its change? As a preservation architect who has rummaged through numerous archives that serve as repositories of a building's life, I have seen this information take on a dizzying array of formats- from scrawls on original drawings, to work orders and memos, to photographs, renovation drawings and reports, repairs hidden in excel spreadsheets and numerous other events that go unrecorded. This paper deals with the issue of representing 'time' architecturally-through an analysis of historical and contemporary examples, it investigates how the life of a building is chronicled. Is there any merit in tracking and representing this change beyond its immediate value of facilitating a modification. Whether and how does the conscious and deliberate 'drawing of time' inform architectural practice?

TIME THROUGH SPACE VS. SPACE THROUGH TIME

For a long time architectural drawing has dealt with the vexing problem of representing 3 -dimensional space on a flat 2-dimensional piece of paper. From perspectives to orthographic projections, drawing techniques employed by architects enable the understanding of volume and enclosure via lines on a plane. Using the example of a 16th century woodcut that shows a curved fortress wall in plan, section and elevation (likely the earliest printed example of these three kinds of architectural drawings shown together), Robin Evans points out how orthographic projections were an established mode of representation by the 16 th century. ${ }^{1}$ By allowing a virtual measurement of all parts of an object before it was built in three dimensions, such drawings facilitated construction and affirmed common building practices. Despite these advances in representation, it was always understood that spatial experience has a fourth dimension-time. ${ }^{2}$ Our kinesthetic experience of a building is not captured in a single view- but in the combination of several views accumulated as we move through space. ${ }^{3}$ Architectural representation has traditionally interpreted the problem of dealing with time, as spatial movement through time. From sketching 'serial views' at various points along a path through a building or site, computer programs in the last two decades have made it commonplace to create 'walkthroughs' that communicate progression through space and time. Virtual reality visualizations allow one to 'inhabit' a space and move through it in time. I call this the architect's response to representing time through (movement in) space and wish to contrast it with representing space through time. The former deals with experiencing space via movement in time while the latter chronicles the building simply as it changes through time. While the former deals with minutes or hours, the latter deals with longer time spans- days, months and even years. The paper posits that while architectural representation has tackled the former question more successfully in various formats, it is still grappling with the complexities posed by the latter.

\section{REPRESENTING TIME IN ARCHITECTURAL DRAWINGS}

Human beings have always had an undeniable need and an innate desire to depict time- from sundials to calendars to clocks and smart-watches; there is an array of devices - all of which deal with representing graphically a rather abstract, ongoing slow form of change. Our entire built world, in various stages of ageing and decay, serves to silently situate us within this continuum of time. This psychological need is behind our desire to retain objects of personal relevance and entire buildings for continual engagement. In her 1953 book Pleasure of Ruins, Rose Macaulay talks of the 'eternal ruin-appetite' that fueled copious depictions of ruins by 
architects and artists at the height of 18th century European Romanticism. ${ }^{4}$ Through picturesque renderings of buildings in advanced stages of decay and weathering, they established ruins as indicators of the passage of time. Writing in 1849, the English writer John Ruskin stated:

For, indeed, the greatest glory of a building is not in its stones, or its gold. Its glory is in its Age... it is in that golden stain of time, that we are to look for that real light, and color, and preciousness of architecture. ${ }^{5}$

From Piranesi's depictions of existing Roman ruins, to Hubert's imaginary painting of the Louvre as a ruin, to Walter Sloane's fictional view of a ruined Bank of England, and similar speculative representations by Albert Speer (Hitler's architect), architectural decay was used to mediate both past and future time. Concerned with how his buildings would endure, Speer proposed the 'Theory of Ruin Value' - stressing that a grand design should degenerate beautifully over time. ${ }^{6}$ In fact, when designing Germania, he was already taking into account how it would look as a ruin, as a monument of the past, resembling the greatness of the Roman Empire. For him, this meant a preference for monumentality and certain materials that he saw as more durable. Yet, whether retrospective or futuristic, ruins represented 'ghosts' of buildings that once were alive- there was a sense of tragic resignation that surrounded their appreciation. They were buildings whose ultimate fate was more or less decided-slow-moving and beautiful -- but hardly fertile grounds for architectural innovation.

This is where depiction of ruins (as picturesque artistic renderings) diverged from those buildings that were in constant use--adapted and added on to through time. Restoration architects and others working on such buildings were most directly confronted with depicting various time periods within singular drawings. A 1571 hand drawing by Tiberio Alfarano represented the Basilica of St. Peters in the Vatican during its Renaissance renovation. The physical superimposition of the New Basilica onto the remains of the Old was reflected in the drawing generated by 'layering'. Alfarano added Michelangelo's ichnographiam above that of the old temple, overlapping and gluing on the outlined plan a cut-out of Etienne Duperac's print reproducing Michaelangelo's plan. ${ }^{7}$ Nicholas Hawksmoor, an English designer in the 18th century, used color coding-grey for existing work, yellow for new construction- a widely adopted convention- for depicting alterations at a historic house. ${ }^{8}$ In a more recent example, for the Conservation Plan for Forty Hall in London, the architect represented various phases of construction on a single floorplan via various hatches and patterns applied to the wall poche. ${ }^{9}$ In another example, colors were applied to a digital 3-dimensional birds-eye model of a 19th century asylum campus in Vermont, indicating building age and building condition, both attributes that serve to graphically display the passage of time. ${ }^{10}$
Humphrey Repton, a 19th century designer and delineator, is particularly well known for his unique architectural renderings that incorporated 'movable flaps' to display 'before' and 'after' scenery. For example his 1808 'View of Proposed Brighton Pavilion', appears at first glance to be an existing view of the house and grounds, but on closer inspection, one can notice movable flaps that flip to reveal proposed buildings. ${ }^{11}$ This technique dramatized the concept of transformation and attempted to dynamically represent change over time. Another technique routinely employed is that of a series of chronological maps, drawn at the same scale and orientation, either stacked or viewed as a 'flip book' to represent temporal transformations. Brian McGrath, in his box set publication of 1994 titled 'Transparent Cities' redrew selected information from different time periods on acetate plates to allow readers themselves to construct multiple images by juxtaposing architectural elements from different eras. ${ }^{12}$

In a follow-up project in 1999 titled Manhattan Timeformations, McGrath used digital 3D modeling and animation software to create an interactive interface about Manhattan's skyscraper history. Much like a 'spatial' timeline, digital skyscraper models are placed vertically on the Z-axis designating the year of their completion while occupying their relative positions in the $\mathrm{X}$ and $\mathrm{Y}$ axes. ${ }^{13}$

Dutch landscape architect Noel van Dooren has amassed an impressive collection of landscape drawings and renderings as part of his doctoral thesis 'Drawing Time' that investigates how landscapes, much more ephemeral and ever-changing when compared to buildings, represent their temporality in a graphic manner. ${ }^{14}$ Critical of the 'all-too-perfect' rendering, Dooren proposes that in a way landscape drawings are 'cheating' us- suggesting a landscape that 'probably never will be there, exactly, in that form'. From plant-calendars to Lawrence Halprin's appropriation of a dance 'score' to landscape representation, Dooren tracks the various ways designers have grappled with the complexity of depicting change over time. He questions, in his own research, the over-reliance on drawings for 'proof that the landscape architect cares about time.' Realizing the over-emphasis this places on drawings, he justifies the attention by contending that 'drawing time' would challenge landscape architects to think more critically about their projects- it might even 'enrich' their projects. ${ }^{15}$

Shifting our focus back to architecture-- since the professionalization of historic preservation in the 1960's, the acknowledgement of the effects of time on buildings has been more deliberate. Architects have documented states of weathering and developed ways to arrest it. In his classic 1994 book How Buildings Learn, Stewart Brand strives to establish architecture's role as a perpetually 'un-finished' project, always adapting and changing in response to its users, to technology, to weather, and so on. ${ }^{16} \mathrm{His}$ ultimate goal was to investigate forms of design that anticipate, or even invite 
change. Mostafavi and Leatherbarrow in On Weathering (1993), and more recently Hilary Sample in Maintenance Architecture (2017) have explored similar issues. While not addressing the process or methods of 'representing' aging, On Weathering implores architectural practice to look beyond the romantic allure of building decay and utilize it as a design feature. Citing the example of the Banca Popolare di Verona (1974-1981) by architect Carlo Scarpa, the authors suggest that the addition of an incised vertical element under each of the circular windows was likely an acknowledgement by the architect of the expected rainwater flow across the façade and his strategic solution to deal with, and plan for it. This is not much different to the earlier and commonplace use of moldings, cornices and drips throughout historical architecture, which as the authors rightly point out were also called 'weathering'-'one word naming both the process and the object through which it was controlled. ${ }^{19}$ So-called 'preservation architects' have been architecturally representing 'weathering' for many decades now. Commonly called 'condition assessment' drawings, these representations usually comprise of building elevations (or rectified photographs) that are copiously marked up with various lines and patterns, showing areas of staining, spalling and cracking. In their notations, quite literally the 'marks of time,' they tell us a great deal about the building's life thus far- what has worked, what has not, that which has changed and that which has stayed on.

Yet, outside the purview of preservation practice, condition assessment drawings are rarely prepared or even studied by 'regular' architects. The understanding of how buildings fare, and thus how to design one, is a more tacit affair, to be learned from passive observation and best practices. Condition assessment drawings also have value as a record of the building's age- usually prepared right before major restoration projects- they are at times the only records of certain episodes in a building's life. Stains that were removed, cracks that were patched, and incongruous additions that were taken down, live on in these documents even when physically absent in the building. Yet, these drawings are not alone in their record of a building's life- they are often accompanied by prolific photographs, investigative reports, product literature and repair schedules. Together, these form the compendium of a building's existence in time. Seemingly mundane, and maddeningly diverse and plentiful, this information is partbiography, and part-service record of the building. If as Brand suggests, we treat buildings as 'expensive tools' meriting careful service and maintenance, ${ }^{20}$ these records of past problems and completed repairs, are important documents that should be chronicled, analyzed and used to inform future work. Repair and maintenance is usually relegated to a lower status than the original act of conceptualizing and creating a building. This dichotomy is well recognized in the architecture profession and reflected in the way a building's life is catalogued. Original construction drawings, especially for significant buildings, are often preserved regardless of whether they represent an accurate account of the building as built. Subsequent renovations are usually tougher to trace- at times they are simply marked up on original drawings or present in work-orders and annual budgets.

Dramatic advances in digital technology have transformed almost all aspects of our personal and professional lives in the last decade- one would assume that the way we chronicle architecture's 'lived reality' has also been influenced. Most large buildings these days are managed and operated by facilities management staff. They register and respond to every building defect- each roof leak, window repair and paint campaign- likely has a virtual record. ${ }^{21}$ However, this data is largely hidden from the 'design' realm and at times even the 'planning and design' divisions within these institutions, primarily tasked with commissioning new buildings are unable to reap benefits from the "lessons learnt..22

In architectural design and representation, parametric 3D modeling, also known as BIM (Building Information Modeling) is now standard practice. ${ }^{23}$ Quite simply, it allows designers to construct a virtual building in all three dimensions, but most importantly, it allows one to attach 'meta-data' or parametric information to each of the building blocks. Herein lies the medium's ability to more directly engage the concept of time, than a purely geometric model would allow. One can easily display the various phases of demolition and construction, link climactic data to study the effects of changing weather conditions and process the flow of energy across time. HBIM or Historic Building Information Modeling, is a term used by some to refer to how BIM can be more specifically applied to modeling existing or historic structures. One of the most interesting applications of HBIM as it relates to 'representing time' can be seen in a system developed by a team of architects working on the restoration of Mount Vernon.

Imagine viewing a three-dimensional model of a room in a historic mansion as it is now on your desktop. Using your mouse, you select an architectural element, such as a door, an archway or molding. Immediately, you obtain relevant information about the element you selected. Quickly, intuitively, you can access searchable data on nearly every component or artifact in a space. You can now find out when the door was made, where the materials and style came from, or how many times the molding was repainted. ${ }^{24}$

Challenges concerning BIM fluency of non-architectural users and the multiplicity of available software platforms have prevented the wholesale adoption of this system as a de facto method of record-keeping for existing buildings. Yet, the larger point remains that advances in management of big data and digital techniques, will soon enable the 'lived' lives of buildings to be more easily chronicled and represented. Whether and how architectural practice will interface with this information, remains to be seen. 


\section{LOOKING BACK AND LOOKING AHEAD}

Throughout this paper, I have tried to analyze approaches to depicting time in architectural representation. This quest stems from the conviction that unless we acknowledge and 'take stock' of an issue, we are rather limited in our ability to respond to it. By making time 'visible' we can study and plan for its effects on buildings. By enabling architects to access the trove of information in a building's biography- regardless of whether they work on renovating existing buildings or not- will enrich the profession. Despite seeming rather self-evident and mundane, lessons 'hidden in plain sight' on weathered facades and aging buildings need to be unlocked and mined. I posit that drawing them (both in analog/digital means) is a quintessentially architectural way of dealing with them- a method that is more involved than simply photographing them. Drawing is not only a means to communicate design ideas to the outer world, it also helps to explore, to generate and to test these ideas in design processes. Trendy computer softwares are able to visualize the effects of changing weather on a building's systems and flows of energy- yet simulations that could help visualize how a building would appear ten, twenty, fifty years from now, are conspicuously absent. Apart from being technically difficult and fraught with speculative ambiguities, one wonders what the larger import of such an exercise might be. The paper suggests that a conscious attempt at 'visualizing' building decay is a worthwhile endeavor- it enables a deeper temporal understanding of buildings, and as an iterative part of the design process it can allow architects to acknowledge and respond to the conditions presented by it.

\section{ENDNOTES}

1 Eve Blau, Robin Evans, and Edward Kaufman, Architecture and Its Image: Four Centuries of Architectural Representation: Works from the Collection of the Canadian Centre for Architecture (Montreal: Canadian Centre for Architecture, 1989).

2 Sigfried Giedion, Space, Time and Architecture: The Growth of a New Tradition (Cambridge, MA: Harvard University Press, 1952).

3 Paul Laseau, Architectural Representation Handbook: Traditional and Digital Techniques for Graphic Communication (New York: McGraw-Hill, 2000).

4 Rose Macaulay, Pleasure of Ruins (Toronto: McClelland and Stewart, 1977).

5 John Ruskin, The Lamp of Memory (New York, 1885).

6 Zeynep Aygen, International Heritage and Historic Building Conservation: Saving the World's Past (Abingdon, UK: Routledge, 2013).

7 Frederica Goffi, Architecture's Twinned Body: Building and Drawing in From Models to Drawings Imagination and Representation in Architecture, eds., Marco Frascari, Jonathan Hale, and Bradley Starkey (Florence: Taylor and Francis, 2013)

8 Blau, Evans, and Kaufman, Architecture and Its Image.

9 Iain McCaig, Conservation Basics (Farnham, UK: Ashgate, 2013).

10 Goody Clancy Architects, Reuse Feasibility Study: Vermont State Hospital, Waterbury, VT, 2012

11 Blau, Evans, Kaufman, Architecture and Its Image.

12 Brian McGrath, "Drawing Time," Architectural Design 86, no. 1 (January/ February 2016): 88-97.

13 Brian McGrath, Inhabiting the Forest of Symbols: From Diagramming the City to the City as Diagram in The Diagrams of Architecture: AD Reader, ed., Mark Garcia (Hoboken, NJ: John Wiley \& Sons, 2010).

14 Noel Van Dooren, Drawing Time: The Representation of Change and Dynamics in Dutch Landscape Architectural Practice after 1985, Doctoral Thesis, University of Amsterdam, 2017.
15 Van Dooren, Drawing Time.

16 Stewart Brand, How Buildings Learn: What Happens After They are Built (New York: Viking, 1994).

17 David Leatherbarrow and Mohsen Mostafavi, On Weathering: The Life of Buildings in Time (Cambridge, MA: The MIT Press, 2001).

18 Hilary Sample, Maintenance Architecture (Cambridge, MA: The MIT Press, 2018). 19 Leatherbarrow and Mostafavi, On Weathering: The Life of Buildings in Time.

20 Brand, How Buildings Learn: What Happens After They are Built.

21 Hippo CMMS, Quick Base, and Service Now are some common proprietary FM softwares that allow managing large facilities.

22 "Federal Buildings: More Consideration of Operations and Maintenance Costs Could Better Inform the Design Excellence Program," report by the United States Government Accountability Office, 2018.

23 Yusuf Arayici et al., eds., Heritage Building Information Modeling, (Abingdon, UK: Routledge, 2017).

24 Quinn Evans Architects, Experiencing Past, Present and Future with HBIM, Report, 2017.

25 English architect Arthur Beresford Pite ([1861-1934] is one of the few known architects who created renderings of proposed buildings in a 'weathered' state. Examples include his proposals for Mission Hall and the West End Club House. 